\title{
Een naald in een hooiberg
}

Citation for published version (APA):

Kolen, A. W. J. (1995). Een naald in een hooiberg. Maastricht University. https://doi.org/10.26481/spe.19951117ak

Document status and date:

Published: 17/11/1995

DOI:

10.26481/spe.19951117ak

Document Version:

Publisher's PDF, also known as Version of record

\section{Please check the document version of this publication:}

- A submitted manuscript is the version of the article upon submission and before peer-review. There can be important differences between the submitted version and the official published version of record.

People interested in the research are advised to contact the author for the final version of the publication, or visit the DOI to the publisher's website.

- The final author version and the galley proof are versions of the publication after peer review.

- The final published version features the final layout of the paper including the volume, issue and page numbers.

Link to publication

\footnotetext{
General rights rights.

- You may freely distribute the URL identifying the publication in the public portal. please follow below link for the End User Agreement:

www.umlib.nl/taverne-license

Take down policy

If you believe that this document breaches copyright please contact us at:

repository@maastrichtuniversity.nl

providing details and we will investigate your claim.
}

Copyright and moral rights for the publications made accessible in the public portal are retained by the authors and/or other copyright owners and it is a condition of accessing publications that users recognise and abide by the legal requirements associated with these

- Users may download and print one copy of any publication from the public portal for the purpose of private study or research.

- You may not further distribute the material or use it for any profit-making activity or commercial gain

If the publication is distributed under the terms of Article $25 \mathrm{fa}$ of the Dutch Copyright Act, indicated by the "Taverne" license above, 
Een naald in een hooiberg

\section{Rede}

in verkorte vorm uitgesproken bij de aanvaarding van het ambt. van gewoon hoogleraar Kwantitatieve Eocnomie,

in het. bijzonder Besliskunde aan de

Rijksuniversiteit. Limburg op)

vrijdag 17 november 1995

door

Antoon Kolen 
$P=14 \% 1 ; \because \because 3)$

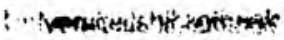

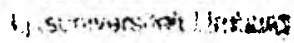


Mijnheer de Rector Magnificus,

Dames en heren, 


\section{Inleiding.}

De naam Besliskunde voor mijn vakgebied is bijzonder goed gekozen. Iedereen kan zich bij het woord besliskunde cen beeld vormen van wat. het. vakgebied inhoudt. Dit, beeld komt naar alle waarschijnlijkheid dichter in de buurt, van de werkelijkheid dan de formele definities, zoals clic o.a. gegeven zijn door de 'Operations Research Society of Amcrica' [1], cn door de 'Operational Research Socicty of Great. Britain' [2]. Ik laat dezc definities dan ook graag onuitgesproken. De Nederlandse naam Besliskunde, voor het internationaal gebruikelijke Operations Research, is voor het cerst in 1957 geintroduceerd door prof.dr.D.van Dantzig in een diësrede, gehonden aan de Universiteit, van Amsterdam [3].

Een declgebied van de besliskunde is de discrete optimalisering. Binnen dit. deelgebied werken aan de Rijksuniversiteit Limburg leden van de vakgroep Kiwantitaticve Economic van de Faculteit der Economische Wetenschappen en Bedrijfskunde samen met. leden van de vakgroep Wiskunde van de Faculteit. der Algemene Wetenschappen. Wij wilden onze onderzockgroep 'Diserete Optimalisering Mikastricht.' noemen. De binnen onze faculteit. gangbare praktijk om groepen met hun afkorting aan to duiden, heeft ons daarvan doen afzien.

In dezc oratic wil ik $\mathrm{U}$ een indruk geven van wat een cliscreet. optimaliseringsproblecm is, welke moeilijkheden zich voordoen bij het oplossen er van, en welke idecën ontwikkcld zijn om dezc mocilijkheden het hoofd te biedon.

\section{Omschrijving discrete optimalisering.}

Mijn voorbeelden van discrete optimaliseringsproblemen komen nit de telecommunicatie en betreffen het toewijzen van frequenties aan basisstations in het. mobiele. telefoonnetwerk. Aan soortgelijke problemen hebben wij de afgelopen twee jaren in het. kader van cen Europees onderzoeksproject. gewerkt [4].

Een mobiele telefoonnetwerk bestaat nit. een aantal basisstations. Elk basisstation is voorzien van een of meer antennes, waarmee een bepaald gebied in de ongeving van het basisstation wordt afgedekt. Wil een gebruiker van het mobiele telefoonnetwerk bellen dan wordt zijn gesprek overgenomen door een van de basisstations binnen het. bercik waarvan gebeld wordt. De hocveelheid gesprekken, welke door cen basisstation gelijktijdig kan worden afgewerkt, hangt af van het. antal frequenties dat voor clat basisstation beschikbarar is. De locaties van de basisstations, het. soort. antenne: per basisstation, en het, aantal frequenties dat. aan een basisstation moet. worden toegewezen, wordt bepaald door de ontwerpers van het mobiele netwerk. Onze taak begint. na het ontwerp en bestaat nit. het bepalen welke specifieke frequentics aan een basisstation moeten worden toegewezen. In mijn voorbeelden ga ik er van uit. dat, aan ieder basisstation precies én frequentic moet, worden tocgewezen. Dit, is geen wezenlijke beperking ten opzichte van de werkelijkheid, omdat als er meerdere frequenties aan één basisstation moeten worden toegewezen, we dit. ook kunnen zien 
als meerdere basisstations op dezelfde locatic, waarbij ann ieder basisstation slechts eén frequentie wordt toegewezen. Twee basisstations kumen elkaar soms storeu. Om storing te voorkomen moeten de frequenties dic aan deze basisstations worden toegewezen cen bepaalde bandbreedte uit elkaar liggen. De beschikbare frequenties verschillen per basisstation, en hebben o.a. te maken met. afspraken met. Junrlanden. Dit betekent dat er in Limburg minder frequentics besthikbaar zijn dan in de randstad. De verzameling frequenties welke beschikbaar is voor een basisstation noemen we het domein van het basisstation.

Een klein voorbeeld, genaamd Voorbeeld 1 , ziet. U in onderstaande Figum 1.

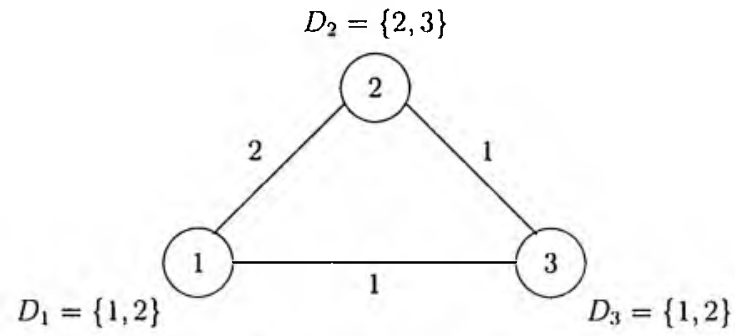

Figuur 1. Probleem instantie Voorbeeld 1.

In Figuur 1 zijn er dric basisstations. Het domein van basisstation 1 (arangegeven met. $D_{\mathrm{l}}$ ) bestaat uit de frequenties 1 en 2; het domein $D_{2}$ van basisstation 2 uit de frequenties 2 en 3 ; en het domein $D_{3}$ van basisstation 3 uit de frequenties 1 en 2 .

In het voorbeeld ziet $U$ dat el lijnen getekend zijn t.ussen sommige paren basisstations. In het voorbeeld zijn dit toevallig alle paren. Een lijn tussen twee basisstations betekent dat er storing optreedt. t.ussen deze twee basisstat.ions indien de afstand tussen de toegewezen frequenties minder is dan de aangegeven waardo. Deze waarde is 2 voor de lijn corresponderende met. de basisstations 1 en 2, en deze waarde is 1 voor de overige lijnen.

Ik noem twee frequentietoewijzingsproblemen gerelateerd aan dit, voorbeeld.

In het eerste probleem is het doel aan ieder basisstation één frequentie uit zijn domein toe te wijzen, zodanig dat. er zo weinig mogelijk storing is. Als maat voor de storing van een frequentietoewijzing nemen we het aantal lijnen waarop storing optreedt.

Het tweede probleem krijgen we indien er storingsvrije oplossingen bestian. In dat. geval wil men graag een storingsvrije oplossing, welke zo weinig mogelijk frequenties gebruikt. 
Beide problemen zijn discrete optimaliseringsproblemen.

Latcn we eens kijken wat deze t.wee problemen gemeenschappelijk hebben om daarnit. de karakteristieken van cen discrect optimalisering af te leiden.

Beide problemen hebben cen cindig aantal oplossingen. Een oplossing is cen frequentictocwijzing, en bestaat uit voor ieder basisstation één keuze uit zijn domein.

We geven met $f_{i}$ de frequentic aan, welke is toegewezen aan basisstation $i, i=1,2,3$. De oplossing $\left(f_{1}, f_{2}, f_{3}\right)=(1,2,2)$ voor Voorbeeld 1 staat. weergegeven in Figuur 2.

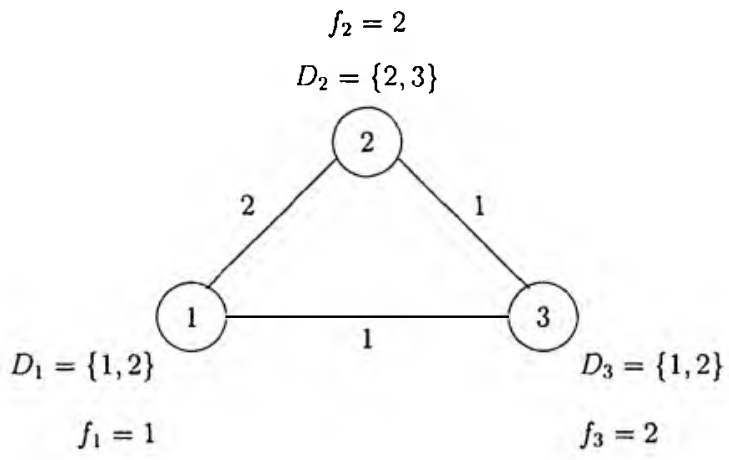

Figuur 2. De oplossing $(1,2,2)$.

Voor beide problemen is een deelverzameling van de oplossingen gegeven, welke we toegelaten oplossingen nocmen. Voor het cerste probleem zijn alle oplossingen toogelaten. Voor het twcede probleem zijn alleen de storingsvrije oplossingen toegelaten.

In beide problemen wordt aan iedere oplossing een waarde toegekend. Voor het cerstc probleem is dat het. antal lijnen waarop storing optreedt. Voor het tweede probleem is dat. het aantal verschillende frequenties.

Voor het ecrste probleem heeft. de oplossing $(1,2,2)$ waarde 2 , omdat storing optreedt op zowel de lijn tussen basisstation 1 en basisstation 2, als op de lijn t.ussen basisstation 2 en basisstation 3 .

Voor het tweede probleem heeft deze oplossing waarde 2, omdat er twee verschillende frequenties voorkomen in de oplossing. 
In Figuur 3 staan alle oplossingen met, voor iedere oplossing de waarde voor beide problemen.

$\begin{array}{ccc}\left(f_{1}, f_{2}, f_{3}\right) & \text { Storing } & \text { Frequenties } \\ (1,2,1) & 3 & 2 \\ (1,2,2) & 2 & 2 \\ (1,3,1) & 1 & 2 \\ (1,3,2) & 0 & 3 \\ (2,2,1) & 1 & 2 \\ (2,2,2) & 3 & 1 \\ (2,3,1) & 1 & 3 \\ (2,3,2) & 2 & 2\end{array}$

Figuur 3. Alle oplossingen.

In beide problemen is de doelstelling het vinden van een l.oegelaten oplossing met. minimale warde. Een tocgelaten oplossing met minimale waarde noomen we een optimale oplossing.

We zien dat. $(1,3,2)$ de unieke optimale oplossing is voor het probleem watarin de storing wordt. geminimaliseerd. Het is tevens de enige toegelaten oplossing, en dis optimale oplossing, voor let, probleem waarin het aantal gebruikte frepurentics wordt. geminimaliseerd.

Samengevat., een probleem is een discreet optimaliseringsprobleem als

1. Het aantal oplossingen eindig is.

2. Voor icdere oplossing is aangegeven of het een tocgelaten oplossing is of nict.

3. Aan iedere oplossing cen waarde is tocgekend.

4. De doelstelling is het vinden van cen toegelaten oplossing van minimale warde.

\section{Moeilijkheid bij het oplossen.}

Wanneer mensen voor het ecrst geconfronteerd worden met een discrect optimaliseringsproblecm zien ze vaak niet waar het problecm ligt. bij het. oplossen van een dergelijk probleem. Het antal oplossingen is immers per definitie eindig. en daarom kan de optimale oplossing worden gevonden door alle oplossingen én voor één t.e bekijken, en steeds de beste toegelaten oplossing tot dan toc bij to houden. 
Voor het. voorbedd betekent, dit. dat we het. lijstje oplossingen in Figuur 3 moeten doorlopen.

Als deze zogenaamde expliciete aftellingsmethode zou werken zou de discrete optimalisering nat.uurlijk nooit. als onderzoeksgebied zijn ont.staan. Een voorbeeld zal duidelijk maken dat deze explicicte aftellingsmethode stuk loopt op het enorme aant.al oplossingen.

Het antal oplossingen voor cen instantic van het frequentietoewijzingsproblecm van het. beschreven type wordt. verkregen door het aantal mogelijke frecunenties per basisstation met elkaar te vermeniguuldigen.

Voor Voorbecld 1 krijgen we dan $2 * 2 * 2=8$ oplossingen.

Dit. kan als volgt. worden ingezien. Voor basisstation 1 zijn er twee mogelijke keuzes voor wat betreft de toe te wijzen frequenties. Bij ieder keuze zijn er twee mogelijke keuzes voor de frequentic, welke toegewezen wordt. aan basisstation 2 . In totaal gecft. dit $2 * 2$ mogelijkheden voor de basisstations 1 en 2 . Bij elk van deze mogelijkheden zijn er weer twee mogelijke keızes voor de frequentic, welke tocgewezen worlt aan basisstation 3 . In totaal zijn er dus $2 * 2 * 2$ mogelijke frequentietoewijzigingen.

Een van de kleinste frequentictoewijzingsproblemen, waaraan wij in curopees verband gewerkt, hebben, bestaat, nit. 200 basisstations met. gemiddeld 40 frequenties per domein. Het aantal oplossingen is dan van de orde van grootte van 10 tot. de macht 320. Aangenomen dat ik duizend computers, die ieder 1 miljoen oplossingen per seconde kunnen doorrekenen, parallel aan het werk zet, dan yijn na 30 jaren ongevecr 10 tot de macht, 18 oplossingen bekeken [5]. Zoals 1 zict. is dat nog maar cen fractic van het. tolakle aantal oplossingen.

De verzameling van alle oplossingen is de hooiberg waar ik in de titel van mijn oratic naar verwijs. De naald die we zoeken is, ofwel een optimale oplossing, ofwel een zo goed mogelijke oplossing indien we optimaliteit. onhaalbaar achten.

\section{Oplossingsideeën.}

Het. vinden van de gewenste oplossing kan alleen maar door een bepaalde st.ruct.unu in de oplossingsruimte aan te brengen. In Sectic 4.1 geef ik cen mogelijke struct.uur voor het geval we cen heuristische oplossing zoeken, dw\% een oplossing die zo goed mogelijk is, maar niet. noodzakelijkerwijs optimaal. In Sectic 4.2 geef ik cen mogelijke structuur indien de optimale oplossing wordt gezocht..

\subsection{Heuristische oplossing.}

Ik wil de structum voor de heuristische benadering inleiden door een vergelijking toe maken met een probleem dat. U waarschijnlijk allemaal veel liever wilt oplossen clan 
het frequentietoewijzingsprobleem, namelijk het vinden van het gezclligste cafect.je in Maastricht. Voor de niet Maastrichtenaren onder ons is het goed om te vertellen dat. dit aantal dermatc groot is dat een expliciete aftellingsmethode gedoemd is te: mislukken.

Wat zou nu een redelijke strategie zijn om toch cen zo gezollig mogelijk areet.je t.e? vinden?

Ik stel de volgende strategie voor. U laat, U afzetten bij cen willekeurig cafeet.je ergens in de stad. Vervolgens bezoekt. $U$ alle cafeetjes in dezelfde straat, cn in alle straten welke verbonden zijn met die straat. Vindt $U$ nergens cen beter cafeet.je dan is het begincafect.je Uw keuze. Vindt. $U$ ergens een beter cafeet.je dan herliailt. U bovenstaande procedure vanuit dat cafeetje. Deze procedure wordt herhaald net. zo lang totdat. $\mathrm{U}$ eindigt in een cafeet.je, welke geen beter cafeet.je in de directe omgeving heeft.

In deze strategie heb ik op de verzameling van alle cafeet.jes een structuur opgelegel, welke ik cen buurstmectutur zal noemen. Voor ieder cafeet.jc is cen declverzameling van alle cafeetjes gedefiniëerd, welke we de burcn van dat cafeet.je noemen. In ons geval zijn dat. alle cafeet.jes in dezelfde straat. of in aanliggende straten. Het zocken naar een gezellig cafcetje speelt. zich steeds lokaal af, namelijk in de gedefiniecrde bunrruimte van het tot dan toe gevonden gezelligste cafeetje. Daarom noemen we cen dergelijkc zoekstrat.egic een lokale zoekmethode. Merk op dat. we nict alle cafeet.jes van Maastricht hoeven te kennen om deze stratcgie te kunnen uitvoeren. Het cnigste wat, we moeten weten zijn alle cafcetjes in de buurruimt.c vall cen gegeven cafeet.je, en deze kunnen wij eenvoudig achterhalen door de betreffende st.raten af te lopen.

Merk op dat. we de definitic van buren zouden kunnen uitbreiden naar alle cafeet.jes in de omringende straatblokken. Het groter maken van de buurruimte heeft tot. gevolg dat. de kans om een gezelliger cafeetje te vinden toencemt, maar dit gaat wel gepaard met meer moeite om alle cafeet.jes in de gedefinieerde buurt t.e onderzoeken. De afweging bij het ontwerpen van ecn buurstructuur is clus enerzijds de kwaliteit. van de gevonden oplossing, en anderzijds de mocite dje het kost deze oplossing te vinden. Nacleel van cleze lokale zockmethode is dat we in cen lokaal optimum t.cecht. komen, namelijk een cafect.je, waar zich geen gezelliger cafectje in de bumrt. bevinclt. Dit. sluit. niet. uit dat, or buiten die bumrt, een nog gezelliger cafectje bestaat.

Voor het frequentietoewijzingsproblecm, waarbij de doelstelling is het minimaliseren van de storing, kan men bijvoorbeeld als buren van cen gegeven oplossing definieren alle oplossingen die slechts in één frequentie van de gegeven oplossing verschilleu. Als we nu een plaatje tekenen waarin we twee oplossingen net elkaar verbinden als het. buren zijn, krijgen we onderstaande figunr. 


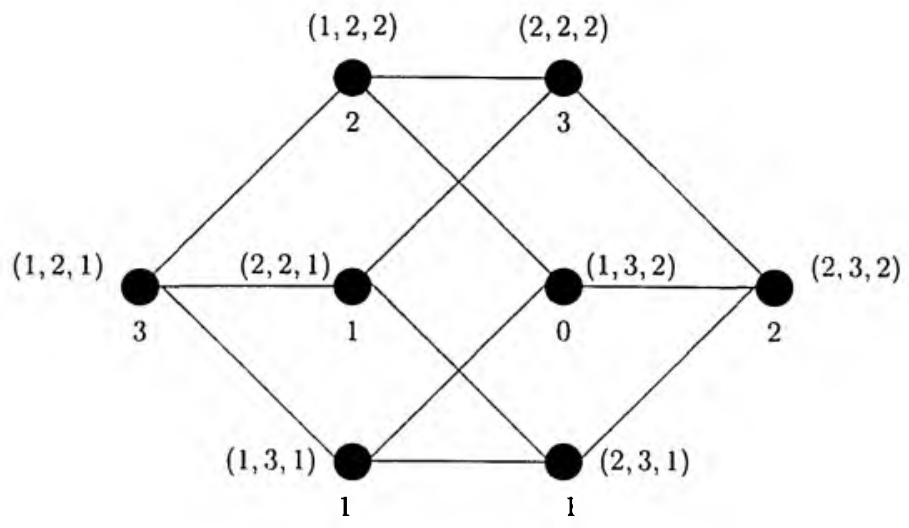

Figuur 4. De buurstructuur.

Starten we in oplossing $(1,2,1)$ met warde 3 dan vinden we onder de drie buren een betere oplossing, bijvoorbeeld de oplossing $(2,2,1)$ met. waarde 1 . We zien dal de lokale zoekmethode eindigt. in deze oplossing ondat er geen betere buuroplossing is. We zien tevens dat we niet het globale optimum vinden, namelijk de oplossing $(1,3,2)$ met. waarde 0 , mar cen lokaal optimum.

Er zijn vele variaties op deze lokale zockmethode ontwikkeld met. als voornatamste wijziging, ten opzichte van het basisidee, de mogelijkheid nit een lokaal optimum to ontsnappen. Simulated annealing, tabu search, threshold accepting, 'n genetische algoritmen zijn enkele van deze varianten. Ik ga daar in deze oratic niet nader op ill.

\subsection{Optimale oplossing.}

Bij het. vinden van een optimale oplossing zien we ons op het eerste gezicht. geplaat.st. voor een onmogelijk taak. Enerzijds kummen we geen oplossing buiten beschonwing laten, het zon immers wel eens een optimale oplossing kunnen zijn, en anclerzijels is het zoals we reeds gezien hebben ondoenlijk alle oplossingen te bekijken.

Bij nader inzien is de taak toch niet zo onmogelijk. We mogen best em oplossing buiten beschouwing laten, mits zich onder sle overgebleven oplossingen ecn exm goede dan wel betere oplossing bevindt. Als we dit. kunnen garanderen kumnen wo 
ook garanderen dat zich onder de overgebleven oplossingen temminste én optimale oplossing bevindt.

Een metlode voor het vinden van een optimale oplossing voor een discreel opt.imaliseringsprobleem, welke gebruikt makkt van bovengenoende obscruat ie, nocmen $w c$, in contrast. met de expliciete aftellingsmethode, ecn implicictc aftellingsmethode. Naar mate de methode implicieter is, d.w.z., meer oplossingen buiten beschouwing laat, is de methode efficiünter.

Een belangrijke vraag met betrekking tot een impliciete aftellingsmethode is op welke wijze we cen garantic kumnen afgeven dat bepaalde oplossingen buiten beschouwing kumnen worden gelaten zonder dat deze oplossingen expliciet worden bekcken.

Ik zal enkele garantiebewijzen illustreren door en impliciet aftellingsinethode to beschreven voor een cenvoudig voorbeeld, namelijk Voorbeold 2 , weergegeven in Figuur 5.

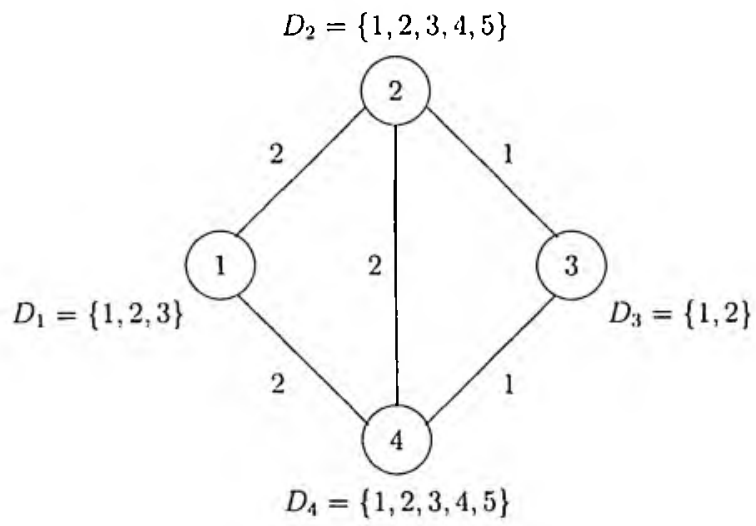

Figuur 5. Probeeminstantic Voorbecld 2.

Discrete optimalisering is een mengeling van wiskunde en puzzelen. Het is juist deze combinatie, welke mij zo veel plezier in mijn vak bezorgt. Het wiskunde karakter komt. in de volgende sectic aan bod. Iets van hel. puzzel karakter vindl. U terug in de nu volgende beschrijving van de impliciete aftellingsmethode. Het. volgen van de redenering vereist. wel jets meer andacht dan bij de meeste oraties gebruikelijk is.

Een impliciele aftellingsmethode begint. met het aanbrengen van structumr in de oplossingsruimte door de oplossingen te verdelen over twee of meer declverzamelingen. 
Voor Voorbeeld 2 \%onden we bijvoorbedel de oplossingen kunnen verdelen in twe: deelver\%andingen, namelijk een deelverzameling warin zich alle oplossingen bovinden watain basisstation 2 een kleinere freguentie toegewe\%en heeft. gekregen clan basisstation 4 , en een deelver\%ameling warin zich alle overige oplossingen hevinden, d.w.\%, alle oplossingen warin basisstation 2 een freguentic toegewezen heeft. gekregen, welke groler of gelijk is an de toegewe\%en [requentic van basisstation 4. De: verdeling statat. weergegeven in Figun 6.

Het. probleen wan het vinden van de oplossing met kleinste watele binnen orn deelverzameling vau alle oplossingen van het oorspronkelijk probleem noemen we een partieel probleem van het oorspronkelijk probleem, de declverzameling is de oplossingsmimte van het particel probleem, en de beste oplossing binnen de dedverzaneling noemen we de optimale oplossing vat het partied probleen. De optimale oplossing van het oorspronkelijk probleem is de beste van alle optimale oplossingen van de partiële problemen. We kumen dus het oorspronkelijk probleem oplossen door ieder van de partiöle problemen op te lossen.

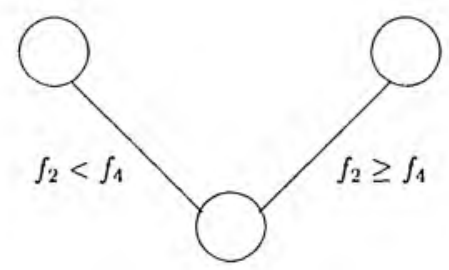

Figuur 6. Partiöle problemen Voorbeelel 2.

We hopen uiteraard dat een aantal partiële problemen nict hoeft te worden onderzocht, omdat een garantie kan worclen afgegeven dat de corresjonderende doelver\%melingen oplossingen buiten beschouwing kunnen worden gelat.en.

Voor Voorbeeld 2 \%ullen we zien dat dit. het geval is voor het particel problexm behorende bij cle extra restrictice $f_{2} \geq f_{1}$.

De initièle verdeling van de oplossingsruimte is de cerste belangrijke stap in do structurering van de oplossingsrumimte. De verdeling moet zoclanig gekozen worden dati het de te gebruiken technicken, om oplossingen van beschouwing uit. t.e shuiten. maximaal onderstemt.

Als alle mogelijkheden om oplossingen buiten beschouwing te laten zijn benut, on het particel probleem nog steeds niet. is opgelost, dan wordt er een fijuere structuur atugebracht in de oplossingsruinte door de oplossingen van het het particel problecm t.e verdelen over een antal deelver\%anelingen. Het partiecl problecm wordt. dam opgelost door de partië]e problemen van bet particel probleem zelf op to lossen. 
Op deze wijze worden alle oplossingen van het oorspronkelijke discrert optimaliseringsprobleem stapsgewijs verdeeld over steeds kleiner wordende declverzanelingen. In het. slechts denkbare scenario moeten we de verdeling door\%enten totelat iedere deelverzameling nit. én oplossing bestant. In dat. geval is cle impliciet.e af tellingsmethode identick aan de expliciete aftellingsmethode. Gelukkig doet dit slechts denkbare scenario zich in de praktijk zclelen voor.

Het. Lotale verdelingsproces voor Voorbeeld 2 staint weergegeven in Figmur 7. Een kruis bij een particel probleem geeft aan dat dit. particel probleem buiten beschouwing kon worden gelaten op basis van de nog nader te beschrijven technicken.

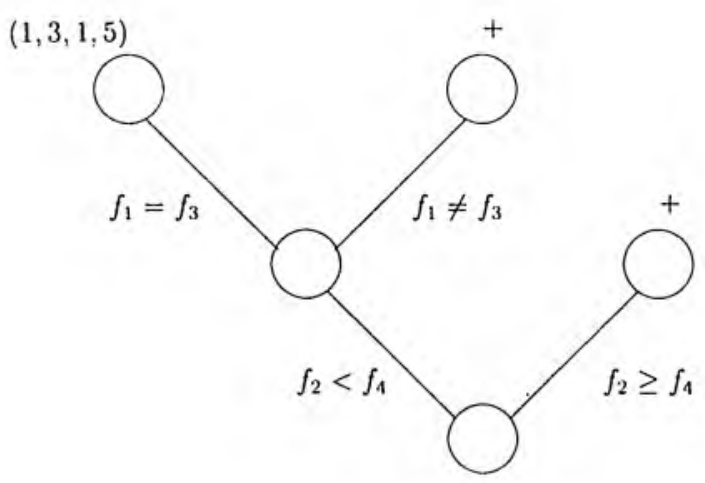

Figuur 7. Verdelingsproces Voorbeeld 2.

Laat. jk de jmpliciete aftellingsmethode, geillustreerd in Figuur 7 nader toclichten. Allereerst. ees toelichting op het feit dat het partiecl problem gedefiniecrol door $f_{2}$ $\geq f_{4}$ buiten beschouwing kan worden gelaten.

De storingsrestrictie tussen cle basisstations 2 en 4 zorgt. er voor dat deze niet dezelfde frequentie toegewezen kumnen krijgen in cen t.oegelaten oplossing. Dit. verklaart. waarom oplossingen, waarbij de basisstations 2 en 4 dezelfde frequentic hebben, buiten beschouwing kmmen worden gelaten. Afgezien van cle onderlinge restrictije, 
zien we dat de basisstations 2 en 4 volledig identiek zijn, d.w.\% ze hebben hetzelfde domein, en dezelfde restricties ten opzichte van de overige basisstations. Dit betekent. dat. als we cen toegelaten oplossing (bijvoorbeeld $(1,5,2,3)$ ) hebben, we een tweede toegelaten oplossing kumen vinden door de frequenties van de basisstations 2 en 4 on te wisselen (bijvoorbecld $(1,5,2,3)$ wordt $(1,3,2,5)$ ). Bij één van deze oplossingen heeft basisstation 2 een kleinere frequentie dan basisstation 4 , bij de andere oplossing lueft basisstation 2 een grotere frequentic dan basisstation 4 . Ondat, beide oplossingen dezelfde waarde hebben, is het toegestaan een van beide oplossingen buiten beschonwing te laten. Gekozen is om de oplossingen, waarin basisstation 2 een grotere frequentie heeft dan basisstation 4 , buiten beschouwing 10 laten. Merk op dat. deze oplossingen buiten beschouwing worden gelaten zonder dat. ze explicict bekeken zijn.

Het gebruikte argument on oplossingen buiten beschouwing te laten is cen illustratic van de techniek dominantie.

Dominantic heeft. betrekking op twee declverzamelingen oplossingen $A$ (n $B$.

Declverzameling $\mathrm{B}$ domineert deelverzameling $\mathrm{A}$ indien voor iedere tocgelaten oplossing in A er en minstens zo gocde toegelaten oplossing is in $\mathrm{B}$.

Als declverzamcling $B$ declverzameling $A$ domineert, dan kan decherzameling $A$ buiten beschouwing worden gelaten.

We kumnen ons bij het oplossen dus concentreren op het partieel problecm corresponderend met de ext.ri restrictic $f_{2}<\int_{1}$.

Bekijken we frequentic 4 in liet domein van basisstation 2 dan zicn we dat er geen enkele frequentic in liet domein van basisstation 4 is, welke an de storingsrestrictice en de restrictie $f_{2}<f_{4}$ voldoet. We concluderen dat er geen enkele toegclaten oplossing is roor het particel problecm, waarbij basisstation 2 frequentic 4 krijgt. toegewezen. We kumnen dus zonder verlies van algemeenheid frecuncut ic 4 uit het. domein van basisstation 2 schrappen. Hetzelfde geldt voor frequentic $\bar{j}$ in het domein van basisstation 2. Tevens kmmen we de frequenties 1 en 2 schrappen uit het domein van basisstation 4 omdat or geen enkele frequentie is in het domein van basisstation 2 zodanig dat an de restrictic $f_{2}<f_{4}$ tussen de basisstations 2 en 4 is voldaan. Het domein van basisstation 2 is dus gereduceerd tot. $D_{2}=\{1,2,3\}$, en het clomein van basisstation 4 is gerechuceerd tot $D_{4}=\{3,4,5\}$.

Kijken we nu naar frequentie 2 in het domein van basisstation 1 dan zien we dat. er geen frequentic is in het domein van basisstation 2 zodanig dat aan de storingsrestrictic tussen de basisstations 1 en 2 is voklaan. We kumnen dus fregnentie 2 nit het domein van basisstation 1 verwijderen. Merk op dat de laatste verwijdering pats mogelijk werd nadat eerst. frequenties $4 \mathrm{en} 5$ uit. het domein van basisstation 2 waren verwijclerd. 
Het. gebruikte argument on frequenties uit een domein van een basisstation to verwijderen, omdat deze frequenties in geen enkele toegelaten oplossing kummen voorkomen, is een illustratie van de technick preprocessing.

Preprocessing is een verzamcham voor allerlei tednicken, wolke toegepast worden on cle probleminstantie te reduceren.

De in het vorbedd gebruike vorm van preprocessing stant bekend als are consistency [0], en is afkomstig uit de informatica.

Het. particel probleem na preprocessing wordt gegeven in Fignur 8.

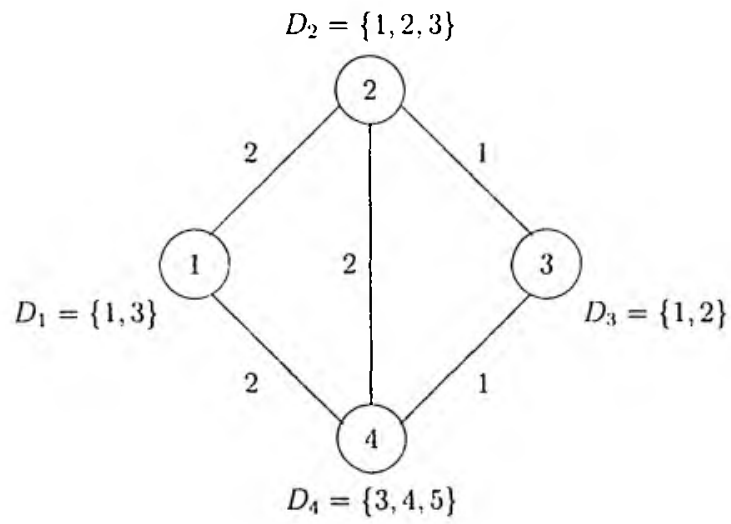

Figuur 8. Particel probleem Voorberel 2 na preprocessing.

Concentreren we ons verder op het partieel probleem in Figunur 8. Oundat het partijeel probleem niet verder reducecrbaar is en ook nog niet. is opgelost, wordt de oplossingsruimte van het particel probleen verder gestructureerd. We verdelen de oplossingen in twee deelverzandingen, nanelijk een deelverzameling oplossingen, watrin basisstations 1 en 3 dezelfde frequentie krijgen toegewezen, en een deelver\%ameling oplossingen, warin basisstations 1 en 3 verschillende frepuenties krijgen tocgeweren. (O) deze wijze ontstan twee nieuwe partiöle problemen, welke onderzocht mocten worden.

We onderzocken allereerst. het partied probleem corresponderend met de extra restrictie $f_{1}=f_{33}$. Omdat de domeinen van de basisstations 1 en 3 slechls frecplentio 1 
gemeensehappelijk hobben, krijgen beide basisstations frepuent.je I toxgewe\%en. Hen particel problexun stati wergegeven in bigunar 9.

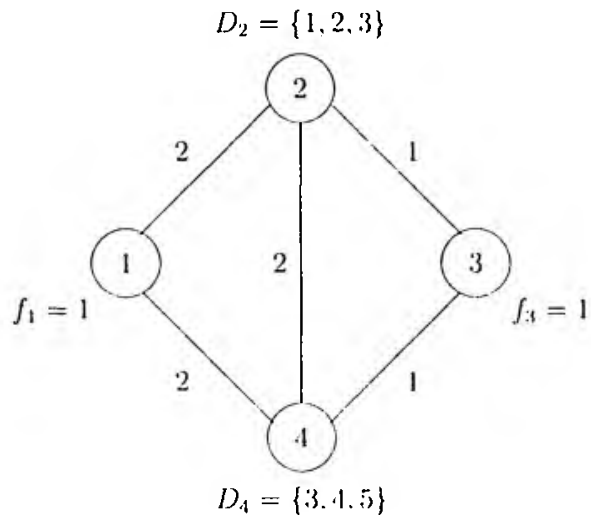

Figuur 9. Particel problexin Voorbeeld 2 bij $f_{1}=f_{3}=1$.

Kijken we natar de storingsrest cictie tussen de basisstations 1 en 2, dan zien we dat. alleen frequentic 3 in het. domein van basisstation 2 daaram volkoet. De freepenties 1 en 2 kumnen dus uit. het domein verwijelerd worden. Als basisstation 2 frecpuent.je 3 krijgt loegewezen kan basisstation 4 alleen frequentie 5 loegewezen krijgen. We vinden dus via preprocessing dat er slechts én toegelaten oplossing is in het particel probleem, en wel de oplossing $(1,3,1,5)$ met waarde 3.

Kijken we nu naar let tweede particel probleem dat, correspondeet. met de extra restrictic $f_{1} \neq f_{3}$. De extra restrictie komt. overeen met. exn storingserestrictio met. afstand 1. Het particel probleem staat. weergegeven in Figun 10. 


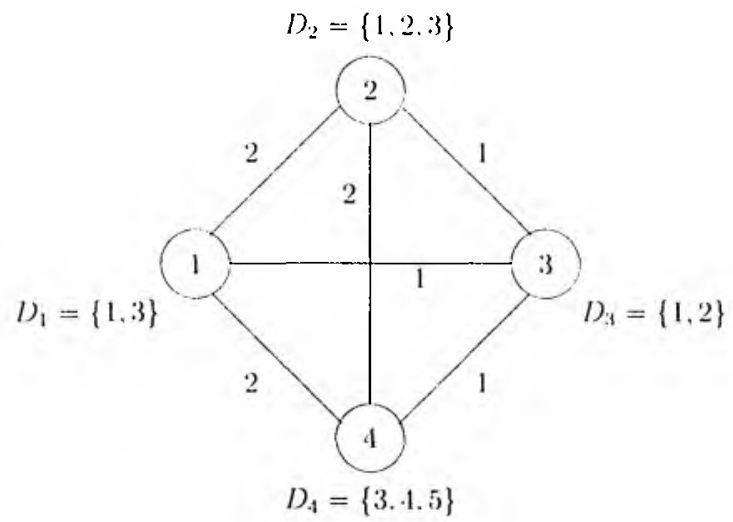

Figuur 10. Particed problecen Voorberld 2 bij $f_{1} \neq \int_{3}$.

Voor ieder tweetal basisstations is er een sloringstestrictie. welke zegl dat de betreffonde basisstations en versehillende frequentio moeten krijgen. ledere loegelaten

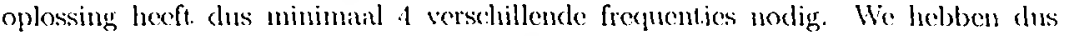
ren ondergrens van f gevonden voor de optimale watarde van hel particed probleen zonder dat we de oplossingen van hes partieel probleem expliciet hobben bekeken. Aangezien deze ondergrens an 4 groter is dan de best. bekende oplossingswatarele ran 3 knunon we dit particel probleen buiten beschouwing laten.

Het gebruikte argument illustreert de tochnick begrenzing.

Voor het toepassen wan begrenzing op een declverzanneling oplossingen zijn lwee watarden nodig. Enerzijds eon ondergrens op cle beste watrde van een oplossing binnen de deelverzameling, en anderzijds de beste watede van alle tot. dan toe bekende oplossingen.

Als de ondergrens groter of gelijk is an de best. bekende oplossingswatarde, ran kumen we conchderen dat. de betrokken dedverzameling oplossingen buiten beschomwing kan worden golaten. De reden walarom we dat. kumnen ionchuderen is weergegeven in Figum 11. Vanwege de clefinitic van de ondergrens weten we dat. alle oplossingen in de deelverzameling en waarde hebben die groter of gelijk is au! de ondergrens. De ondergrens zelf is weer groter of gelijk anu de besile bekende oplossingswatrde. We combluderen dat. geen enkele oplossing in de declverzameling beter is dan de tot dan toe best bekende oplossing. 


\section{Wiatede}

$$
\mid \begin{aligned}
& \rightarrow \text { Beste oplossingswatrde declveryaneling } \\
& \rightarrow \text { Onclergrens declverzaneling } \\
& \rightarrow \text { Watarde beste bekende oplossing }
\end{aligned}
$$

Figuur 11. Begromzing.

ludien de ondergrens kleiner is dan de best bekende oplossingswatarde kummen we geen garantic afgeven dat. de betrokken declveratuneling bniton beschonwing kan worden gelat.en. Er kunnen zich in dat geral twee sit.uaties vordon. In de con situatio is de onbekende beste warde van een oplossing bimnen de derdver\%ancling kleiner dan de wararde van de best. bekende oplossing (zic Finumr 12), ('n in diat geval geven we terecht geen garantic: af.

$$
\begin{aligned}
& \text { Waardo } \\
& \qquad \begin{array}{l}
\rightarrow \text { Waarde best. betende oplossing } \\
\rightarrow \text { Beste oplossingswatde deelverzanneling } \\
\rightarrow \text { Ondergrens declveratueling }
\end{array}
\end{aligned}
$$

Figuur 12. 'Teresht geen garantic.

In de andere situatic is de onbekende beste oplossingswratde in de declverzanneling groter of gelijk an de best. bekende oplossing (zic Figunr 13), en in dat geval wordt ten ourechte geen garant ie afgegeven.

$$
\begin{aligned}
& \text { Waarde } \\
& \qquad \begin{array}{l}
\rightarrow \text { Beste oplossingswatarde declver\%uneling } \\
\rightarrow \text { Waatcle best bekende oplossing } \\
\rightarrow \text { Ondergrens deelver\%anding }
\end{array}
\end{aligned}
$$

Figuur 13. Ten onrechte geen garantice.

De situatic in Figuur 13 toont, aan clat. het zaak is een ondergrens te berekenen die: zo dicht mogelijk bij de beste waarde van de deelverzameling in de buurt. komt. Dit. om situaties watrin we ten ontechte geen garantic afgeven te vermijden. Over het algemeen geldt, echiter dat, des te beter de ondergrens des te meer tijd het kost om deze t.e berekencu. Deze extra tijd moet altijd afgewogen worden tegen de tijdswinst. clie met een betere ondergrens wordt geboekt, namelijk de besparing in het zoeken naar oplossingen binnen cle deelverzameling, welke anders buten besehouwing zou zijn gelat.en. 


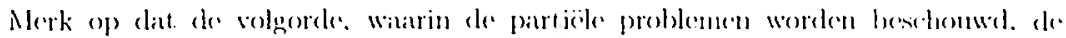

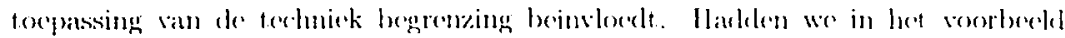

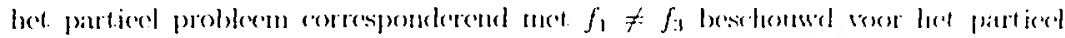

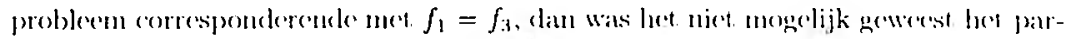

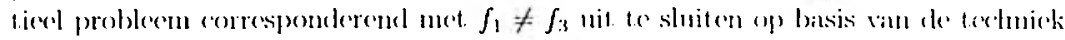

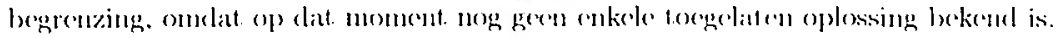

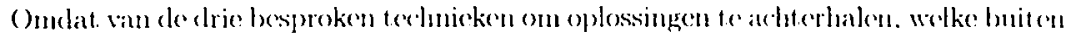

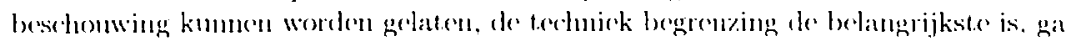

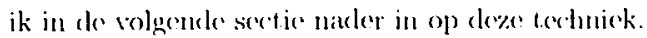

\section{De techniek begrenzing.}

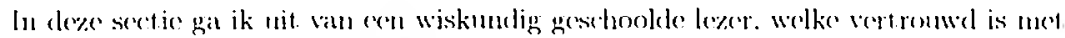
wiskimelige mokellon en met grafentherie.

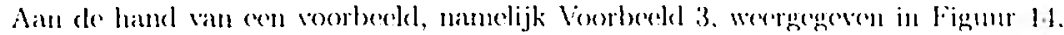
besprese ik ern serje tomentencle ondergrenzen.

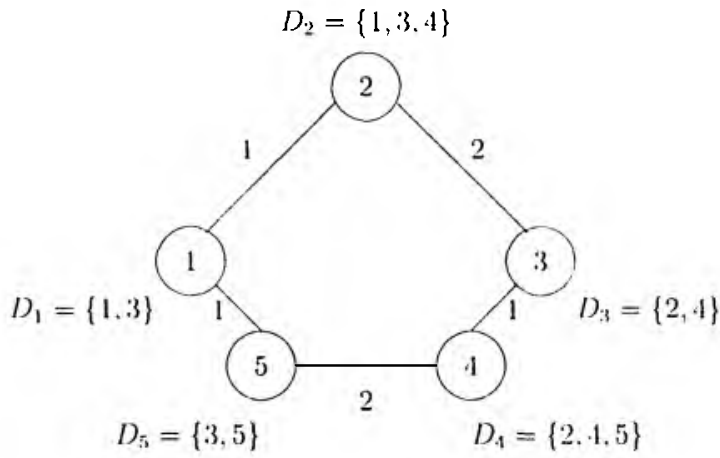

Figuur 14. Problecminstiantic Vonberlel 3.

We beginnen met een combinatorisele ondergrens, welke we ook reets in de enrige

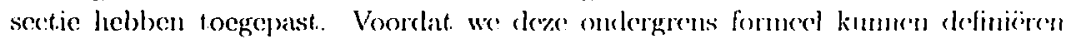
allereerst. enkele definitics. 
De restratie granf corresponderende met een instantie van het frepuntitictoewijzingsprobleem leeft een punt voor ieder basisstation, en en lijn voor ieder tweetial basisstations watartussen een storingsrestrictie bestaat.

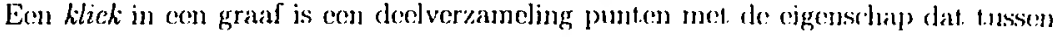
iocler tweelal punten in de kliek een lijn bestaat.

Een maximum kliek is cen klick met maximum cardinaliteit.

Een kliek in de restrictic grataf correspondeert met. cen deelverzaneling basisstations met de cigenschap dal. tussen ieder tweetal basisstalions in de kliek on storingsrestrictio bestaat. In iedere toegelaten oplossingen is het aantal versehillende frequentics toegeweyen aan een kliek gelijk aan het, aantal basisstations in de klick. De cardinaliteit van con maximum klick is clus een ondergrens voor hot. nantal verschillende frequenties dat. in iedere tocgelaten oplossing voorkont. Wo noemen deze: ondergreus de klickondergrens.

Voor Voorbeeld 3 is de kliekondergrens gelijk an 2.

Elk van (le overige ondergrenzen is gebaseerd op een relixitio van lact op to lossen probleem.

Problecm $B$ is een releutatie van probleem $A$ als voldaan is an de volgende twee cisen.

1) Iedere toegelaten oplossing van $\Lambda$ is ook tocgelaten in $B$.

2) Iedere toegelaten oplossing van $\Lambda$ heeft in probleen $B$ cen watade die kleiner of gelijk is aan de watarde die deze oplossing heeft in problecm $A$

Merk op dat. de watarde van een oplossing dus kan verschillen in de problemen $A$ en B. De twe eisen gezamenlijk garanderen dat. de optimale oplosisingswatarde van probleem $B$ kleiner of gelijk is an de optimale wate van probleem $A$. Dit is cenvondig in te zien als men bedenkt, dat de optimale oplossing wn problecm $A$ tevens toegelaten is in probleern $B$ (eis 1), en daar cen kleiner of gelijke waarde: heeft (eis 2). De optimale waarde van de relaxatic B kan dus dienen als ondergrens voor de optimale waarde van $\Lambda$.

Een manier om een relaxatic van een probleem te verkrijgen is on do watarde van een oplossing onveranderd te laten (aan cis 2 is dan automatisch voldatan), en een aantal restricties te versoepelen (aan eis 1 is dan voldaan). Voorbecklen voor hel. frequentietoewijzingsprobleem zijn het verlagen van de bandbreedte alstand bij een lijn, en hel. toevoegen van frequentics an cen domcin.

$\Lambda \mathrm{ls}$ tweede ondergrens nemen we het kleuringsgetal van cle restrictic graaf. Het kleuringsyetal van ecn graaf is het minimaal antal kleuren dat. nodig is om iexler punt. van de graaf een kleur te geven zodanig dat twee punten, welke verbonden zijn door een lijn, een verschillende kleur hebben. 
Het is envoudig in te zien dat. let. klentingsproblem en rolixatio is van het frequentietoewijzingsprobleen. Iedere toegelaten oplossing corresponderet. met cen toegelaten kleuring door voor iedere gebruikte frequentio een kleur te reserveren. Twoe punten, welke verbonden zijn door een lijn, hebben een versehillende klenr. ondat. zij in de toegelaten oplossing een versehillende frequenlie lebben vanwege de onderlinge storingstestrictic. Aan eis 1 van een relaxatic is dus voldaan.

Aan eis 2 is voldaan, ontat cen toegclaten oplossing in beide problemen dezelfde watarde heeft.

Het. is niet. moeilijk in te zion dat. het klenringsgelal van de restrictic graaf corresponderende met Voorbeeld 3 gelijk is aan 3.

De derde ondergrens is gebaseerd op de relaxatie van het frequentiotoewijzingsprobleem, waarbij als er cen storingrestrictic is de bij deze restrictie behorende bandbreedte afstand gelijk wordt genomen aan 1. Ilet verschil met. het kleuringsproblecm is dus dat. in deze relaxatie de domeinen gelijk zijn aan die in het oorspronkelijke problecm. De bewering is dat. we minimal vier frequenties nodig hebben. Dit. kan als volgt. worden ingezien. De basisstations 1, 3, en 4 hebben alle een verschillende frequentie in iexere toegclaten oplossing. Voor basisstation 3 en 4 geldt dit omdat ze verbonden zijn door een storingrestrictice, voor basisstations $1 \mathrm{cn} 3$ geldt dit. ondat. de domeinen geen gemeenschappelijke frequentic bevat.len, en voor basisstations 1 en 4 geldt dit ook ondat. de domeinen geen gemeenschappelijke frequentics bevatten. Als er en oplossing is met drie frequenties moet basisstation 5, welke verbonden is met. basisstation 1 en basisstation 4, een frequentie hebben, welke verschilt van dic van deze beide basisstations. Basisstation 5 moet. dus de overgebleven frequentice hebben, en zoals we zagen heeft. ook basisstation 3 deze frequentic. Dit. is edlter onmogelijk ondat. de doncinen van de basisstations 3 en 5 geen gemeenschappelijke frequenties hobben. Iedere tocgelaten oplossing heeft dus minimal vier frequenties nodig. Een toegelaten oplossing voor de relaxatic met waarde 4, en dus een optimale: oplossing, is $(1,3,2,4,3)$.

De laatst.e twee ondergrenzen corresponderen met relaxatics gebaseerd op $(0,1)$ programmeringsformuleringen van het frequentietoewijzingsprobleom. We cluiden deze relaxaties an met respectievelijk de snede methode on kolomgeneratic.

We besclirijuen eerst. de snede methode. 
Een toegelaten oplossing van het. frexuentictoewijxingsprobleem kumnen we weergeven via cen $(0,1)$-vestor, waarbij een coördinaat is gereserveerd voor iedere combinatic van frequentie on basisstation (een 1 geeft. aan dat. het basisstation de frecinentio krijgt tocgewezen, ecn 0 geeft. aan dat. het. basisstation de frequentic: niet. krijgt. toegewezen), en tevens cen coördinaat. is gereservecrd voor iedere mogelijke frepuentic (cen 1 geeft, aan dat, deze frequentic wordt gebruikt, cen 0 geeft. ath dat. deze frequentie niet wordt. gebruikt).

We gebruiken de volgende notatie om de coördinaten van de $(0,1)$-vertoren, welke de toegelaten oplossingen representeren, weer t.e geven.

$$
\begin{aligned}
& x(i, f)= \begin{cases}1 & \text { als frequentie } f \text { an basis station } i \text { wordt toegewezen, } \\
0 & \text { anders }\end{cases} \\
& y(f)= \begin{cases}1 & \text { als freguentic } f \text { wordt gebruikt. } \\
0 & \text { anders }\end{cases}
\end{aligned}
$$

Een bekend resullaat. nit. de polyhedrale theoric (zie stelling van Farkis, Minkowski en Weyl in hoofdst.uk 7 van het, boek van Schrijver[7]) zegt. chat. het. convex omlnilsel van alle $(0,1)$-vectoren, welke corresponderen met. toegelaten oplossingen, kan worden beschreven door een stelsel lineaire ongelijkheden. Gegeven dit stelsel lineaire ongelijkheden kan het. frequentictoewijzingsprobleen gesclıreven worden als een lineair programmeringsprobleem, en opgelost, worden met. cen van de efficiönte oplosmethoden voor lineaire programmeringsproblemen. De optimale oplossing van het. lincaire programmeringsproblecm is tevens de optimale oplossing van het. frequentictoewijzingsprobleen. Het. probleem bij deze aanpak ligt in het. vinden van de lineairo ongelijkheden, welke het convex omhulsel beschrijven. In de praktijk zijn we slecht.s in st.ant cen deelverzameling van deze ongelijkheden te beschrijven. We lossen in de praktijk dan ook een relaxatic op van het. probleem door ons te beperken tot. een deelverzameling van alle lineaire ongelijkheden. In de gangbare oplossingswijze beginnen we met cnkele ongelijkheden, waaraan de toegelaten oplossingen moet.en voldoen. Vervolgens wordt het lincaire programmeringsprobleem met de\%e ongelijkheden opgelost. Voldoet de optimale lineaire programmeringsojlossing ook aan alle overige bekende ongelijkheden dan stopt de procedure. Volkloet de optimale lineaire programmeringsoplossing niet. aan alle overige bekende ongelijkheden dan worden de ongelijkheden, welke gesehonden zijn alsnog toegevoegd en de procedure herhaalt. zich. Deze methode wordt de snede methode genoemd ondat de toegevoegde ongelijkheden de oude lineaire programmeringsoplossing afsnijden van het resterende toegelaten gebied. De reden om niet alle bekende ongelijkheden in het begin al toe t.e vocgen ligt in het enorme aantal ongelijkheden, en het feit dat. slechts enkele van deze ongelijkheden bindend zijn voor de optimale lineaire programmeringsoplossing, aan de overige ongelijkheden wordt, door de optimale lineaire programmeringsoplossing altijd voldaan. Vanwege de efficiëntic van de lineaire programmeringsoplossingstechniek wordt daarom het aantal toegevoegde ongelijkheden zo beperkt. mogelijk 
gelouden.

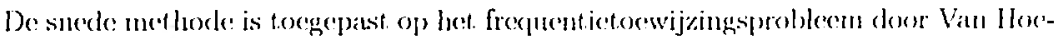
sel en andere [8]. Ik illustreer hum anupak voor Voombodil:3.

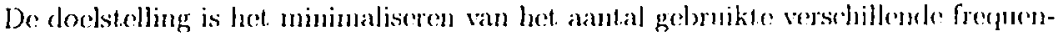
ties, en kan $m$ geformulecrel worden als

$$
\text { minimaliseer } \sum_{J} y(f)
$$

In de restrieties moeten we vastleggen dat iecler bessisstation én frequentie nit zijn clomein krijgt. toegeweren. Dit. wordt afgedwongen door de volgende restricties

$$
\sum_{f \in D,} x(i, f)=1, \text { voor alle } i
$$

We mocten een relatic leggen lussen het toowijzen van een frequentie aan een batsisstation en het gebrnik van dege frequentic. Deze relatio wordt vastgelegd in de volgende restricties.

$$
x(i, f) \leq y(f) \text {, wor alle } i \text {, en voor alle } f \in D_{2} \text {. }
$$

Als frequentie $f$ wordt gebruikt is er en basisstation $i$ met $f \in D$, wanroor $x(i, f)=$ 1. De restrictie dwingt dan af dat $x(i, f)=1 \leq y(f)$, m.it.w, $y(f)=1$.

De storingsrestricties worden gemodeleerd door

$$
\begin{array}{ll}
x(i, f)+x(j, g) \leq 1, & \text { voor alle }\{i, j\}, \text { en voor alle } f \in D_{i}, g \in D_{3} \\
& \text { met. }|f-g|<d(i, j),
\end{array}
$$

waarbij $d(i, j)$ de bandbrecelte afstand is behorende bij de storingsrestrictio tussen busisst.ations $i$ en $j$.

Als de frequenties $\int$ voor basisstation $i$, en $g$ voor basisstialion $j$ niet aan de storingsrestrictic voldoen, dan kan maximaal én van deze frepuentietoewijzingskeuzes gemalakt. worden.

De eis dat. iedere variable een niet-negatieve watarde heeft, d.w.\%,

$$
\begin{aligned}
& x(i, f) \geq 0, \text { voor alle } i, \text { en voor alle } f \in D_{i} \\
& y(f) \geq 0, \text { voor alle } f,
\end{aligned}
$$

complementeert de initiele lineaire programmeringsformulering.

De optimale lineaire programmeringsoplossing wordt gegeven cloor 


$$
\begin{aligned}
& y(1)=y(2)=y(3)=y(4)=y(5)=0.5, \\
& x(1,1)=x(1,3)=0.5 \\
& x(2,1)=x(2,3)=0.5 \\
& x(3,2)=x(3,4)=0.5, \\
& x(4,2)=x(4,4)=0.5, \\
& x(5,3)=x(5,5)=0.5 .
\end{aligned}
$$

De relaxatie heft. watarde 2.5 .

Een ongelijkheid, welke geschonden wordt sloor de hnidige optimale lineaire prograumneringsoplossing is de ongelijkheid

$$
x(1,1)+x(2,1) \leq y(1) .
$$

Deze ongelijklıcid \%egt dal. indien frequentice 1 niet. worlt gebruikt, d.w.,,$y(1)=0$. frepuentic 1 niet kan worden tocgeweron aan basisstations 1 en 2. De ongelijkheiel zegt. dat, indien frecuentie 1 wel wordt gebruikt, (l.w.\%, $y(1)=1$, frequent je 1 slechts aan én van beide basisstations I en 2 kan worden toegewezen, dit. omdat er cen storingsrestrictic bestaat. thssen dewe twee basisstations.

De klasse van ongelijkheden, waitrtoe de\% ongelijkhoid bohoort, kan beschreven worden door

$$
\sum_{i \in C} x(i, f) \leq y(f) \text {, voor alle } f \text {, en alle klicks } C \text { in cle graaf } G(f),
$$

De graaf $G(f)$ is een graaf met als punten alle basisstations, watabij $f$ in het domein zit, en als lijnen alle paren, welke niet dezelfde frepuentio toegeweren kumuen krijgen. De restrictio \%egt dat. als frequentie $f$ wordl. gebruikt, de\% frecuentice nan slechts ćn basisstation in een klick in $G(f)$ kan worden toegewezen.

Bovengenoemde klawse van ongelijkheden bevat in het voorbedkl de wolgende 7 ongelijkheden.

$$
\begin{aligned}
& x(1,1)+x(2,1) \leq y(1) \\
& x(1,3)+x(2,3) \leq y(3) \\
& x(2,4)+x(3,4) \leq y(4) \\
& x(3,2)+x(4,2) \leq y(2) \\
& x(3,4)+x(4,4) \leq y(4) \\
& x(4,5)+x(5,5) \leq y(5) \\
& x(1,3)+x(5,3) \leq y(3)
\end{aligned}
$$

Vanwege het geringe aantal ongelijkherlen, voegen we ze allemaal toe, en niet. slechts diegene welke geschonden zijn door de optimale lineaire programmeringsoplossing. De optimale lineaire programmeringsoplossing van het nieuwe model is 


$$
\begin{aligned}
& y(1)=y(2)=y(1)=1 . y(3)=y(5)=0.5 \\
& x(1.1)=1 \\
& x(2.3)=x(2,4)=0.5 . \\
& x(3.2)=x(3,1)=0.5 . \\
& x(4.2)=x(4,1)=0.5 \\
& x(5,3)=x(5,5)=0.5 .
\end{aligned}
$$

D) rolaxaltie hoeft wiatrde 1 .

Een ongelijkheid, welke geschenden wordt door de hudige optimale linenire programmoringsoplosinge is

$$
x(2,3)+x(2,4)+x(3.1) \leq 1
$$

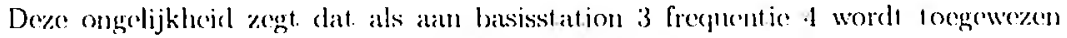
$(x(3,4)=1)$ men niet freepentice 3 of 4 anan basisstation 2 kan toewijzen. ondat de\%e

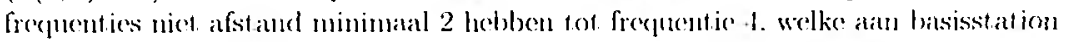
3 is tocgewe\%en. Dege ongelijkheid zegt verder dat. als aan basisstation 3 frepultutio

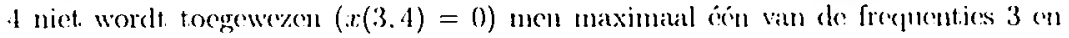
4 aan basisstation 2 kan toowij\%en. Dit komt oreren met de cis dat slechts con frephentio nit. het slomein kan worden gekomen.

Do klasse wan ongelijkherlen. Waartoo de\%e ongelijklıeid behoort. kan beschreven worden door

$$
\sum_{f \in F} x(i, f)+x(j, g) \leq 1
$$

voor alle lijuen $\{i, j\}$, vor alle $g, g \in D_{j}$, en $F . F \subseteq D$, gedefiniend door $F=$ $\{f \in D,|| f-g \mid<d(i, j)\}$.

Bovengenoemde kiasse ongelijkheden bevat. voor het voorberdel de volgende 4 ongelijkheden

$$
\begin{aligned}
& x(2,3)+x(2,4)+x(3,4) \leq 1 \\
& x(3,2)+x(3,4)+x(2,3) \leq 1 \\
& x(4,4)+x(4,5)+x(5,5) \leq 1 \\
& x(5,3)+x(5,5)+x(4,4) \leq 1
\end{aligned}
$$

Na toevoeging van alle ongelijkheden in deze klassse, vinclen we de volgencle oplimale lineaire programmeringsoplossing

$$
\begin{aligned}
& y(1)=y(2)=y(3)=y(4)=y(5)=1 \\
& x(1,1)=1 \\
& x(2,4)=1 \\
& x(3,2)=1 \\
& x(4,5)=1 \\
& x(5,3)=1
\end{aligned}
$$


De relaxatide heeft waarde 5 .

Aangezien de optimale oplossing van de lineaire programmeringsrelaxatic toegelaten is in het. $(0,1)$-programmeringsprobleem, is deze oplossing optimat ioor het. $(0,1)$ programmeringsproblecm.

De latatste relaxalie is kolomgeneratic.

De kolomgencratic tedmick is gebasecrd op en $(0,1)$-programmeringsformulering wan het probleem. De relaxatice van het model is de standaard lineaire progrannmeringsrelaxatic, watabij de eis dat de variabelen de watarde 0 of 1 kumnen anunemen wordt vervangen door de eis dat. de watude van een variabele tussen 0 on 1 moet liggen. De kunst. is mu een $(0,1)$-programmeringsformulering te vinden voor het probleem, watrvan de optimale watede wat de lineaire programmeringrelaxalio dicht. ligt bij de optimale watrele van het. $(0,1)$-programmeringsporoblecm. Ervaring heoft geleerd dat. dit. vaak mogelijk is bij $(0,1)$-programmeringsformuleringen met een zeer groot. anutal variabelen. Een lineair programmeringsproblecm met en groot. antal variabolen kan worden opgelost met de zogenaande kolomgenenatie techmek. In deze technick wordt. in hes. begin een lineair programmeringsproblecm ojgelost. waarbij een atutal variabelen uit. het problecm wordt weggelaten. Vervolgens is het. mogelijk na te gatan of er variabelen zijn, welke ten ouredste zijn weggelaten. Een wariabele is ten onredte weggelaten als het lineaire progranuneringsprobleenn nat 1.oevoeging van deze variabele en betere optimale watale hest das hert problecm voor toevoeging. Eon lineair programmeringsprobleem wordt vaak in matrixvorm geschreven, watarbij de rijen corresponderen net de restricties en de kolonmen mot. de variabelen. Daaron word1. het vinden van eon variabele, welke ten onrechte is weggelaten nit. het probleem, het kolomgeneratie probleem genoend. Zijn on variabelen, welke ten onredhte \%ijn weggelaten, dan worden de\%e alsnog toegevoegd, Dit. herhatalt zich totdat geen cukele variabele ten onrechte is weggelaten, en in dat. geval is het lineaire programmeringsprobleem optimalal opgelost. Voor meer informatic over de theorelische en praktische achlergronden wn kolongenenatic wordt. verwezen naar Savelsbergh [9].

Voor de lineaire programmeringsrelaxatie van ecn discrees optimaliseringsprobleem is het kolomgeneratie probleem vaak zelf weer ecn discreet optimaliseringsproblecm. Ondat het kolomgeneratie probleem een groot aantal keren moet worden opgelost., kan de technick alleen zinvol worden toegepast. indien het kolomgenerat.io probleom effeiënter oplosbaar is in de praktijk dan het oorspronkelijke discrect optimaliserings]roblecm.

We illustreren het een en ander aan de hand van Voorbeeld 3.

Als we een toegelaten frequentietoewijzing beschouwen dan vormt de verzaneling van alle basisstations, welke dezelfde gegeven frequentic hebben toegewe\%en gekregen, een onaflankelijke verzameling in de restrictic graaf. Een onafhantelijke verzameling in een graaf is cen declverzameling punten met de eigenschap dat geen enkol 
twere punten verbonden is door en lijn.

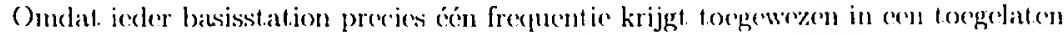

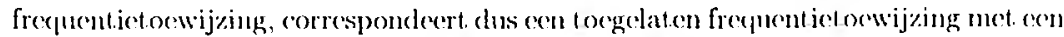
partitie wan cle ver\%anding basisst at ions in cen antal onaflankelijke verzamelingen. In onze (0,1)-programmeringsformulering an het. frequentio toewijzingsploblenn atsociëren we dan ook een variabele net iedere onafhaukelijke verzantuding in cle restrictie graaf met de cigenschap) dat. ann ieder basisstation in de\%e onathankelijke veryameling dezelfde freguentie kan worden toegewezent.

We gebruiken de notatie If voor de verzameling van alle onafhankelijke ver\%anelingen waram frefuentic $f$ kan worden toegeweren.

We introduceren de volgende $(0,1)$-variabelen

$$
r(f, S)= \begin{cases}1 & \text { als freculentie } f \text { wordt toegeweren an onafhankelijke } \\ & \text { verzameling } S, S \in I_{f} \\ 0 & \text { anders. }\end{cases}
$$

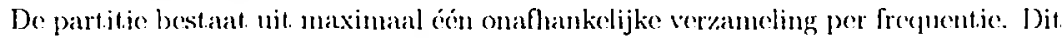
kan geformuleced worden als

$$
\sum_{S \in I,} x(f, S) \leq 1, \text { voor alle } f .
$$

Iedere basisstation moet in precies én onaflaukelijke verzaneling voorkomen. Dit. kau geformuleerd worden als

$$
\sum_{f \in D,} \sum_{S \in I_{f}: i \in S} x(f, S)=1 \text {, voor alle } i .
$$

Restrictics (1) en (2) modelleren het feit dat. we cen partitie hebben van de basisstations in onafhankelijke verzamelingen. Echter niet iedere partitio van de basisstations in onafhankelijke verzamelingen vormt een tocgelaten frequentictoewijzing. We moeten immers de storingsrestricties nog modelleren. Do storingstestrictie 1.ussen basisstations $i$ en $j$ regt clat nit. iedere combinatie van freguenties $f, f \in D$, on $g$, $g \in D$, met $|f-g|<d(i, j)$, er maximaal én geko\%en kau worden.

Dit. kan gedefiniecrl worden als

$$
\sum_{S \in I_{j}: i \in S} x(f, S)+\sum_{S \in I_{g}: j \in S} x(g, S) \leq 1,
$$

voor alle lijnen $\{i, j\}$ in de restrictic graaf, en alle $f \in D_{n}, g \in D$, zodanig das $|f-g|<d(i, j)$.

De doelstelling is het. minimaliseren van het antal frequenties. Onchat, vanwege restricties (1), maximaal ćén onafhankelijke verzameling per frequentie gekozen kan worden, correspondeert de doelstelling met. het. minimaliseren van het aantal onafhankelijke verzannelingen in de partitic.

Dit. kan gemodelleerd worden als 


$$
\text { Minimaliseer } \sum_{f} \sum_{S \in I_{f}} x(f, S)
$$

Passen we deze formulering toe oj) Voorbeeld 3.

We hebben de volgende 14 variabelen $x(1,\{1\}), x(1\{2\}), x(2,\{3\}), x(2,\{1\}), x(3,\{1\})$, $x(3,\{2\}), x(3,\{5\}), x(3,\{2,5\}), x(4,\{2\}), x(4,\{3\}), x(4,\{4\}), x(4,\{2,4\}), x(5,\{4\})$ en $x(5,\{5\})$.

Restrictic (1) voor frequentic 3 hidit

$$
x(3,\{1\})+x(3,\{2\})+x(3,\{5\})+x(3,\{2,5\}) \leq 1
$$

Restrictie (2) voor basisstation 4 luiclt.

$$
x(2,\{4\})+x(4,\{4\})+x(4,\{2,4\})+x(5,\{4\})=1
$$

Restrict.je (3) voor freçuentic 2 bij basisstation 2, en frecfuentic 4 bij basisstal.ion 3 luidt.

$$
x(3,\{2\})+x(3,\{2,5\})+x(4,\{3\}) \leq 1 .
$$

De optimale oplossing van de lincaire programmeringsrelaxatice wordt. gegeven door

$$
\begin{aligned}
& x(1,\{1\})=1 \\
& x(2,\{3\})=x(2,\{4\})=\frac{1}{2} \\
& x(3,\{2,5\})=\frac{1}{2} \\
& x(4,\{2,4\})=x(4,\{3\})=\frac{1}{2} \\
& x(5,\{5\})=\frac{1}{2}
\end{aligned}
$$

De waarde van de relaxatic is 4 .

Kijken we nader naar restricties (3) dan valt op dat we de\%e restricties kumuen verst.crken. Voor een gegeven lijn $\{i, j\}$ in de restrietie grataf, en een gegeven frequentic $f \in D_{i}$ kunnen we de deelverzameling $F_{i j}^{f}$ vin $D_{j}$ definiëreu als alle frequentics wolke niet samen met $f$ aan de restrictic voldoen, m.a.w.

$$
F_{i j}^{f}=\left\{g \in D_{j}|| f-g \mid<d(i, j)\right\}
$$

Restrieties (3) kunnen dan vervangen worden door

$$
\sum_{S \in I_{\text {g }} ; \in \in S} x(f, S)+\sum_{g \in F_{1,}^{\prime}} \sum_{S \in I_{g}: j \in S} x(g, S) \leq 1
$$

De optimale oplossing van de lineaire programmeringsrelaxatic van deze nieuwe formulering wordt. gegeven door 


$$
\begin{aligned}
& x(1,\{1\})=1 \\
& x(2 .\{3\})=1 \\
& x(3,\{5\})=1 \\
& x(4,\{2\})=1 \\
& x(5,\{4\})=1
\end{aligned}
$$

De relaxatie: leefl. wialde 5 .

Aangexien de optimale lineate progranceringsformulering toegelaten is in let (0.1)programmeringsproblecm is dit, de optimale oplossing.

Om de watade wan de relaxatie te berekenen zijn alle variabelen in loet model opgenomen. Voor grotere problecminstanties is het ommogelijk om alle variabelen mee te nemen, onclat. het aantal variabelen eenvoudig te groot. is. We mocten dan de ecreder bescheren kolomgeneratice terhuck toepassen. In dowe oratic gat ik niet. nader in op het kolomgeneratie probleem.

\section{Dankbetuiging.}

Het cincle van een orat ie is een mooi moment even terug te blikken op cle afgelopen jaren. Ik zie af rau een volledig overzicht en volsta met. enkele opmerkingen.

Voor het. feit dat. het. Nexlerlindse onder"ock op het gebied van de discrele optimalisering internationaal zo goed statat angeschreven is Ian-Kard Lenstra op do allereerste: platts verantwoordelijk. Porsoonlijk ben ik hem ook dank verontschuldigd, ondat. mijn cerste kenuismaking met de discrete optimalisering plats.s vond op het. Mathematisch Centrum in Amsterdim, war hij mij als promovendus had abugenomon.

De afgelopen periode was ondenkbaar gewest zonder Mirjam. Al meer dan twintig jaren is zij en stimulerende kraclut.

Tenslotte wil ik niet de rol vergeten, welke niju twee zoontjes Niels en Martijn in mijn leven spelen. Ik hoop dat. zij nog lang mijn aandacht. blijven opvragen.

Ik heb geregd. 


\section{Verwijzingen.}

11] De 'Operations Researeh Society of America' geeft de volgende definitio van Operations Research. "Operations reseneh is concemed with scientifically deciding how to best design and operate man-machine systems, usinally under conditions requiring the allocation of scarce resources".

[2] De 'Operations Research Sociely of Great. Britain' geeft. de volgende definitic van Operational Research. "Operational research is the applieation of the methods of science to (omp)] $x$ problems arising in the direction and management of large systems of men, machines, materials and moncy in industry, business, government, and defence. The distinctive approath is to develop it sciontific: model of the system, incorporating measurements of factors such ats chance and risk, with which to predict and compare the ontcomes of alternative decisions, strategies or controls. The purpose is to help management determine its policy and actions scientifically".

[3] De diësrede van prof. dr. D. van Dantzig heeft. als titcol "Reeckeningh in spelen van geluck" en is nog steed verkrijgbanr bij de Universiteit. van $\Lambda$ ntsterdam.

4] Aan het. C $\triangle$ LMA (Combinatorial Algorithms for Military Applications) project werd deelgenomen door onderzockleams nit de landen Engeland, Frankrijk.

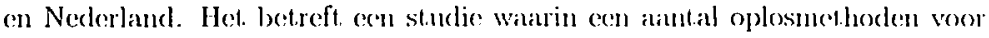
discrete optimaliseringsproblemen wordt. vergeleken met betrekking tot. hes. freculentictoewijzingsproblecm.

[5] Het antal oplossingen is ongeveer $40^{2001}$.

$40^{200}=2^{400} * 10^{200}=\left(2^{10}\right)^{40} * 10^{200}$.

$2^{10}=1024$ is ongeveer $10^{3}$.

Dus $40^{200} \approx\left(10^{3}\right)^{40} * 10^{200}=10^{320}$.

Hel, aantal door te rekenen oplossingen is gelijk an het aantal seconden in 30 jaren vermenigvuldigl. met $10^{9}$, zijnde het aanlal oplossingen dat duizend computers per seconde kunnen doorrekenen.

Het aantal seconden in 30 jaren is gelijk an het anutal seconden per dag (86400) vermenigvuldigt. met het. aantal dagen in 30 jaren (ongeveer 10950), en is ongeveer gelijk aan $10^{5} * 10^{4}=10^{9}$.

Het aantal door te rekenen oplossing is dus ongeveer gelijk aan $10^{18}$.

[6] Meer informatic over de geschiedenis van arc-consistency en corresponderende algoritmen kan gevonden worden in het. artikel "Are-consistency and arr: consistency again" van C. Bessière, Artificial Intelligence 65 (1994), 179-190.

[7] Zie voor meer informatic over polyhedrale theorie het bock "Theory of linear and integer programming" van A. Schrijver, Wiley (1986). 


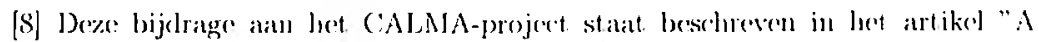
Branch \& Cut algorithm for the frecpueney assignument problon" ran Aatial. K., B. Jausen, A. Ilipolito \& $S$. van Hoesel.

[0] Zie het artikel van "Branch-and Price: Cohumn (iomeration for Solving Inge Integer Programs" van C. Barnhat,, E.L. Johnson, (i.L. Nemhatuser, M.MV.P. Savelsbergh \& P.H. Vance in het. bock "Mathemalical Programming: State of the Art 1994" wat .1.R. Birge \& K.G. Morty (The University of Michigan). 